\title{
Epidemiologia da cólera em Moçambique no período de 1973-1992
}

\author{
Cholera epidemiology in Mozambique: period 1973-1992
}

\author{
Miguel Aragón ${ }^{* \star}$, Avertino Barreto**, Philippe Tabbard ${ }^{\star \star *}$, Jonas Chambule*, Clara Santos ${ }^{\star \star \star \star}$, António Noya ${ }^{\star \star \star *}$
}

\begin{abstract}
ARAGÓN, M. et al. Epidemiologia da cólera em Moçambique no período de 1973-1992. Rev. Saúde Pública, 28: 332-6, 1994. São descritos os resultados de estudo epidemiológico da evolução da cólera em Moçambique no periodo de 1973 a 1992, com o objetivo de analisar a influência dos fatores socioeconômicos e ecológicos, de um país em guerra, na propagação da doença. Foram utilizadas informações relativas à incidência e letalidade da cólera, relacionando-as com a taxa de crescimento médio anual da população das cidades e precipitação pluvial. Foram analidos também o abastecimento de água potável, o saneamento do meio e higiene alimentar. Encontrou-se uma taxa elevada de crescimento médio anual da população nos centros urbanos, tendo uma correlação linear direta com a incidência da cólera. A seca ocorrida em 1991-1992 também exerceu papel importante no aumento e propagação da doença. A cólera tem tido padrão endêmico-epidêmico, determinado por: a) crescimento populacional urbano descontrolado, provocado pela guerra; b) redução da qualidades das condições higiênico-sanitárias nos centros urbanos; c) comercialização de produtos alimentares sem o devido controle sanitário; d) a seca.
\end{abstract}

Descritores: C6́lera, epidemiologia. Ecologia. Fatores socioeconômicos.

\section{Introdução}

A história epidemiológica da sétima pandemia, iniciada há 32 anos nas Ilhas Celebes, na Indonésia, atingiu o continente Africano, em 1970'. Em1991, verificou-se uma recrudescência da doença, na África, e em setembro do mesmo ano tinha-se notificado total de 102.000 casos em comparação com os 72.415 casos notificados em $1971^{12}$. O agente etiológico da doença o $V$. cholerae biótico EL TOR, necessita ser encarado como um microrganismo de elevada tendência para a endemicidade dada a sua capaciadade de sobrevivência no meio ambiente ${ }^{13}$.

A República de Moçambique teve uma populacão estimada, em 1992, de 15.036.143 habitantes* e uma extensão territorial de $799.300 \mathrm{Km}^{2}$. Localizada na costa oriental da África Austral, apresenta um dos PIB mais baixos do mundo", devastada por uma

* Progama de Emergência. Ministério de Saúde de Moçambique

** Departamento de Epidemiologia e Endemias. Ministério de Saúde de Moçambique

*** Save the Children U. K. Ministério de Saúde de Moçambique

**** Gabinete de Epidemiologia. Ministério de Saúde de Moçambique.

Saparatas/Reprints: M. Aragón - Gabinete de Epidemiologia. Av. Eduardo Mondlane/Salvador Allende Maputo - Moçambique guerra que durou mais de 16 anos.

Em Moçambique, a cólera apareceu pela primeira vez em 1973, na Cidade de Maputo, propagando-se posteriormente pelo país durante as últimas duas décadas. O perfil epidemiológico do país, nos últimos anos, reflete e acompanha a evolução socioeconômica e ecológica, pelo que, o objetivo do presente trabalho é fazer análise epidemiológica para verificar como esses fatores influenciaram a propagação da cólera na País.

\section{Material e Método}

Foi feito um estudo epidemiológico descritivo da cólera em Moçambique, no período compreendido entre 1973 a 1992, cujas variáveis analisadas foram as seguintes: incidência e letalidade da cólera; dados demográficos; dados meteorológicos; dados sobre a cobertura do abastecimento de água potável, saneamento ambiental e higiene alimentar.

De 1973 até 1990 foram considerados pelo Ministério da Saúde, como sendo casos de cóleras aqueles confirmados bacteriologicamente. A partir de 1991 a definição de casos de cólera mudou. Atualmente, com critérios clínicos e na possibilidade de haver confirmação bacteriológica da presença do $V$. cholerae,

* Comissão Nacional do Plano/DNE/DD/PROJ/MOZ 91/ P01/PNUD. 
ainda que de um único caso suspeito num distrito, todos os casos de diarréia com desitração grave do mesmo destrito, são notificados como casos de cólera e o distrito é declarado "afetado". Depois de 2 meses (8 semanas) sem registros de novos casos, o distrito será declarado "livre da epidemia".

Os dados de notificação da cólera foram coletados pelo Gabinete de Epidemiologia da Direção Nacional de Saúde do Ministério da Saúde, através do Boletim Epidemiológico Semanal (BES), enviado por todas as Unidades Sanitárias do País. A informação demográfica foi obtida na Comissão Nacional do Plano/Direção Nacional de Estatística e Demografica. Os dados relativos à precipitação pluvial foram fornecidos pelo Instituto Nacional de Meteorologia, correspondendo às médias mensais dos anos 1990 a 1992. As informações ligadas ao saneamento do meio e à qualidade da água canalizada foram obtidas no Departamento de Higiene Ambiental do Ministério da Saúde.

Foi relacionada a incidência e letalidade da cólera, assim como a precipitação pluvial e a incidência da cólera nos anos de 1990-1992. A análise da correlação entre o crescimento populacional urbano e a incidência da cólera foi feita com base nas taxas de crescimento médio anual da população dos centros urbanos do país, entre 1980-1991. Para os registros de cólera, a análise foi feita com base nas taxas médias de incidência da cólera desses mesmos centros urbanos, nos anos

Tabela 1. Taxa de incidência/100.000 hab. e letalidade da cólera. Moçambique, 1973-1992.

\begin{tabular}{cccc}
\hline Ano & $\begin{array}{c}\text { Taxa de } \\
\text { Incidência* }\end{array}$ & $\begin{array}{c}\text { Taxa de } \\
\text { Letalidade }\end{array}$ & $\begin{array}{c}\text { Distritos } \\
\text { Afetados }\end{array}$ \\
\hline 1973 & 8,2 & 11,9 & $\ldots$ \\
1974 & 0,0 & 0,0 & $\ldots$ \\
1975 & 0,03 & 33,3 & $\ldots$ \\
1976 & 0,08 & 25,0 & $\ldots$ \\
1977 & 0,2 & 16,7 & $\ldots$ \\
1978 & 0,0 & 0,0 & $\ldots$ \\
1979 & 7,9 & 12,1 & $\ldots$ \\
1980 & 4,4 & 7,6 & $\ldots$ \\
1981 & 7,1 & 7,8 & $\ldots$ \\
1982 & 18,4 & 9,7 & $\ldots$ \\
1983 & 86,8 & 4,2 & $\ldots$ \\
1984 & 4,2 & 2,1 & $\ldots$ \\
1985 & 0,0 & 0,0 & $\ldots$ \\
1986 & 0,0 & 0,0 & $\ldots$ \\
1987 & 0,0 & 0,0 & $\ldots$ \\
1988 & 0,0 & 0,0 & $\ldots$ \\
1989 & 2,7 & 3,2 & 3 \\
1990 & 29,3 & 4,7 & $\ldots$ \\
1991 & 54,7 & 4,2 & 45 \\
1992 & 211,0 & 2,4 & 52
\end{tabular}

Fonte: Boletim Epidemiológico Semanal (BES) DNS, Ministério da Saúde-Moçambique.

...Dados não disponíveis.

*World Health Organization, Center for Disease Control, Atlanta, Georgia. Epi Info Versão 5.01a-March 1991.

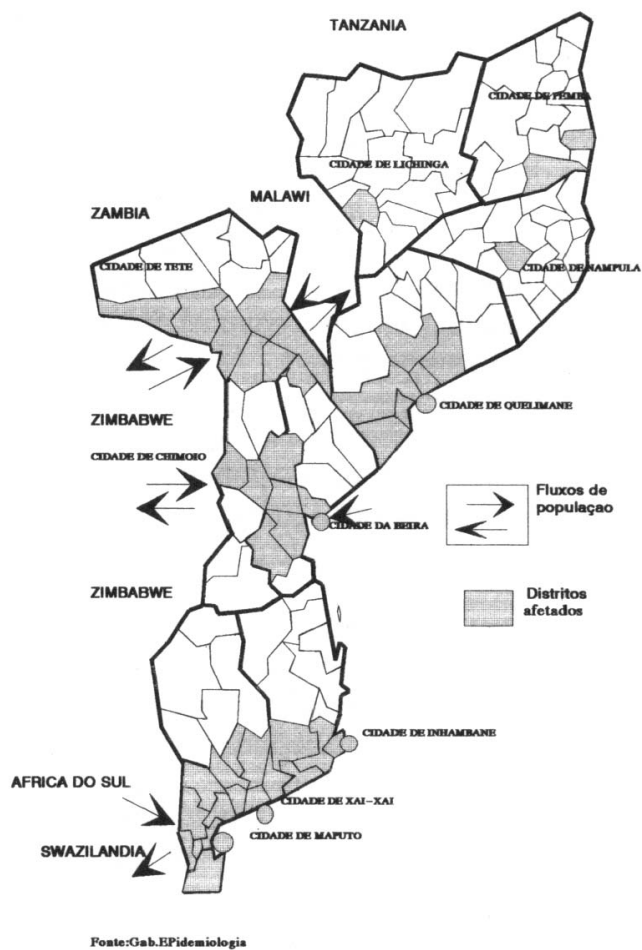

Figura 1. Mapa dos distritos afetados pela cólera 1991 1992, Moçambique.

1991 e 1992, utilizando o programa Epi-Info*.

\section{Resultados}

A epidemia de cólera afetou, em 1973, 5 províncias do país, registrando-se 753 casos e 90 óbitos. De 1975 a 1977 apareceram alguns casos esporádicos, num total de 29, dos quais foram registrados 6 6bitos. A partir de 1979 a doença ocorre praticamente sem interrupção até 1984. Depois de um período de 4 anos, ressurgiu em 1989 na Cidade de Tete, Província de Tete, estendendo-se aos distritos de Moatize e Changara da mesma província. Os casos notificados de cólera incrementaram-se de 371 , em 1989, a 31.731 , em 1992 , com uma taxa de incidência de $2,7 / 100.000$ hab. e 211/100.000 hab., respectivamente. Apesar da taxa de incidência ter tendência ao aumento nesta duas décadas, a taxa de letalidade tem um comportamento decrescente (Tabela1). O número de províncias e distritos afetados pela cólera também aumentou durante o mesmo período, com maior incidência nas capitais de província e nos distritos onde passam as principais vias de comunicação e se verificam maiores aglomerados populacionais (deslocados, refugiados, e outros) (Fig. 1). Das análises laboratoriais realizadas, foi isolado o V. cholerae, biótipo EL TOR, sendo identificados os dois serotipos: Inaba e Ogawa. Os 
anos de 1981 e 1982 foram marcados pela resistência in vitro do $V$. Cholerae à tetraciclina e sulfadoxina, principalmente nas Cidades de Maputo e Beira. Em 1990 registrou-se novamente na Cidade da Beira, província de Sofala, resistência in vitro à tetraciclina.

De 1980 a 1991 a população dos 12 centros urbanos do país cresceu de 1.555 .342 habitantes a 2.952.638. respectivamente, com uma taxa de crescimento médio anual de $4,5 \%$, contra $2,5 \%$ ao nível do país durante o mesmo período. Analisando as Taxas Médias de Incidência de cólera, de 1991 a 1992, nesses centros urbanos, e relacionando-as com as Taxas de Crescimento Médio Anual da população urbana, encontrou-se uma correlação linear direta (coeficiente de correlação $=0,63$; intervalo de confiança de $95 \%=$ $0,09<\mathrm{R}<0,88$ ) (Fig. 2).

Durante os anos de 1990-1992 observou-se maior incidência dos casos de cólera nos meses do período chuvoso e quente, com exceção do ano de 1992 em que houve maior incidência no período seco e frio, comparado aos anos anteriores (Fig. 3).

Dos 143 sistemas de abastecimento de água canalizada existente no pais, foram inquiridos 69 pelo Departamento de Higiene Ambiental do Ministério de Saúde em dezembro de 1992. Em 81\% dos sistemas inquiridos, não existia ou não estava em funcionamento nenhum sistema de tratamento de água canalizada para o consumo humano; $64 \%$ abasteciam-se inteira ou parcialmente através de fontes superficiais (rios, lagoas, nascentes, e outras); e em $78 \%$ o pessoal de saúde informou que as entidades respónsaveis pelo sistema de abastecimento de água não podiam proceder à desinfecção por falta de produtos químicos (HTH) (Tab. 2).

\section{Discussão}

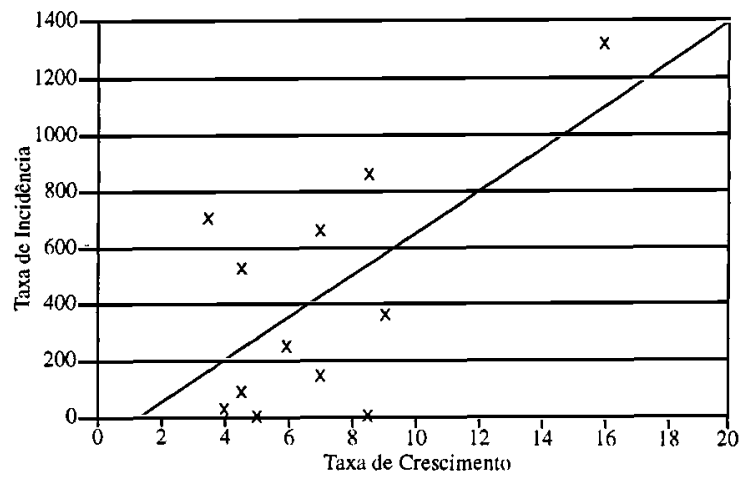

Figura 2. Correlaçăo entre urbanização e cólera. Moçambique, 1990-1992.

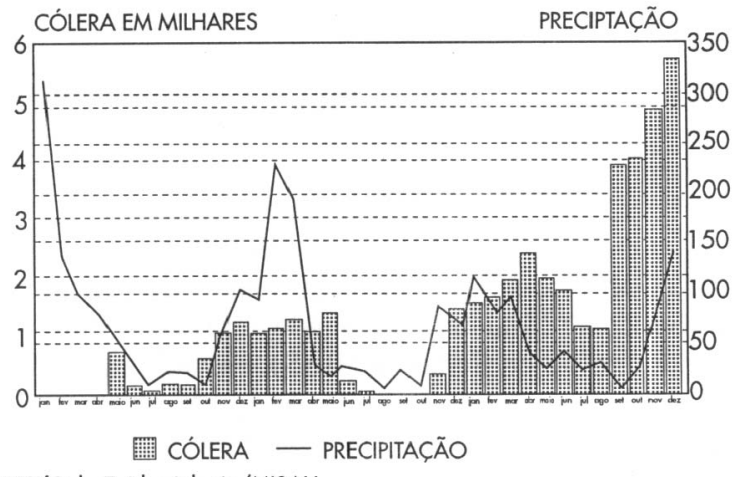

BES/Gab. Epidemiologia/MISAU

Figura 3. Cólera e precipitação pluvial. Moçambique 1990 1992.

A análise epidemiológica da cólera no presente estudo tem uma abordagem ecológica multicasal. Tem sido observado um incremento do número de casos, assim como da taxa de incidência, e uma rápida propagação pelo território nacional, apesar de registrar taxas baixas de letalidade em relação às reportadas no Continente Africano ${ }^{2,12}$. Dentre as principais atividades que o Sistema Nacional de Saúde, em Moçambique, tem desenvolvido para a diminuição da taxa de letalidade, figuram: formação do pessoal de saúde no tratamento da desidratação grave; definição do caso de cólera; melhoramento da vigilância epidemiológia na identificação de surtos; produção e distribuição de normas de prevenção e tratamento da cólera; elaboração e ditribuição de "Kits" com os principais materiais necesários para o tratamento dos doentes; organização de comissões nacional, provinciais e distritais de luta contra a cólera com a participação intersetorial e a intregação com o programa nacional de controle das doenças diarréicas (CDD). Se é verdade que foi mencionada a resistência à tetraciclina, em baixa proporção in vitro, em algumas cidades do país s.5 $^{3.5}$, esta não foi reportada in vivo, pelo que não é possível afirmar se esta exerceu papel determinante na propagação pelo país. Mas considerou-se que a mudança na definição de caso de cólera teve influência no aumento de casos e óbitos notificados durante os anos 1991 e 1992. Contudo, esse

Tabela 2. Resultados da avaliaçāo de 69 sistemas de abastecimento de água - Moçambique, dezembro 1992.

\begin{tabular}{lcc}
\hline $\begin{array}{l}\text { Sistema de } \\
\text { Abastecimento }\end{array}$ & Sim & Năo \\
$\begin{array}{l}\text { Sistema de } \\
\text { tratamento de água } \\
\text { Fonte de abaste- }\end{array}$ & $13 \ldots(19 \%)$ & $56 \ldots(81 \%)$ \\
$\begin{array}{l}\text { cimento superficial } \\
\text { Desinfecção de }\end{array}$ & $44 \ldots(64 \%)$ & $25 \ldots(36 \%)$ \\
$\begin{array}{l}\text { água com HTH } \\
\text { Fonte: Departamento de Higiene Ambiental DNS/MISAU. }\end{array}$
\end{tabular}


aumento acompanhou o registrado no Continente Africano, que reportou em 1991, 9 vezes mais o número de casos que em qualquer outro ano dessa pandemia ${ }^{12}$. Entretanto, este aumento permite a aproximação da cifra real dos casos e, sobretudo, facilita realizar um melhor tratamento dos doentes baseados na gravidade da desidratação, pois os casos notificados são os de diarréias que necessitam tratamento intensivo, permitindo ter uma visão mais completa das necessidades de material e pessoal.

Moçambique, depois de um longo período de guerra, onde a economia do país foi gravemente afetada e a população rural em busca de segurança abandonou o seu próprio sistema de subsistência, trocando-o por condições menos favoráveis de vida (centro de deslocados, refugiados em países vizinhos $^{6}$ e zonas periféricas das cidades), transformouse num ambiente hostil, favorável à explosão de doenças infectocontagiosas e carenciais. O resultado óbvio é que, para além do pequeno ensaio matemático de cólera, estes têm sofrido importante crescimento demográfico, a "numa situação fluída e descontrolada de distribuição territorial da população, em que a mobilidade constante e desordenada é a característica fundamental, é inevitável que a produção e o ambiente refletem essa mesma característica" (Araújo $\left.{ }^{1}, 1992\right)$. Na cidade de Quelimane também foi encontrada uma correlação positiva significativa entre as taxas de incidência dos bairros e a densidade populacional ${ }^{4}$. "O movimento centrípeto da população em direção ao centro supera, em grande medida, a força centrífuga do espaço urbano para a periferia" (Araújo1, 1992), espaço este, com serviços básicos escassos ou ausentes, como: água, habitação, falta de plano regulador urbanístico, trabalho e educação. Por exemplo, a cobertura de abastecimento de água potável à população urbana passou de $48 \%$ em 1980 para $33 \%$ em 1990*. Nas zonas rurais, a maioria da população continua a abastecer-se de água superficial (rios, riachos, lagoas, e outros) e/ou poços tradicionais, sem medidas de proteção. Estima-se que a cobertura de água potável nas zonas rurais é de $17 \%$ da população ${ }^{11}$.

$\mathrm{Na}$ maioria das zonas urbanas, os sistemas de esgotos existentes não fucionam adequadamente. Nas zonas periféricas, onde se encontra concentrada a população deslocada, é freqüente o fenômeno de fecalismo a céu aberto. Nas zonas rurais é também muito freqüente este fenômeno, e a ultilização e construção de latrinas tradicionais não garante suficientemente a proteção contra vetores. Apesar de todas essas

*Actas da Primeira Reunião Nacional de Abastecimento de Água, fevereiro 1991, Maputo.

** UNICEF. Projecto Corredor da Beira: construção de 4.000 latrinas. 1992. pp:1.

*** Goverment of Mozambique/UN. Mozambique Emergency Drought Appeal 1992-1993. May 1992. pp:14. dificuldades, o Programa de Saneamento a Baixo Custo construiu e distribuiu 76.876 latrinas aperfeiçoadas, de 1979 a 1991, beneficiando 615.008 pessoas, mas que representam menos de $5 \%$ da população do país**. A incorreta deposição final do lixo é um problema que afeta principalmente as zonas urbanas e periféricas do país, agravado pela escassez de viaturas destinadas à remoção do lixo, falta de espaço ou solo não adequado para o aterro sanitário e ausência de educação sanitária sobre o correto manuseio do lixo pela população.

$\mathrm{O}$ crescimento do mercado informal ("DumbaNengues" e/ou "Chumgamoio", em línguas locais) nos centros urbanos do país, em particular os produtos alimentares pré-confeccionados, têm facilitado a comercialização dos mesmos sem o controle sanitário adequado.

Do ponto de vista climático, a cólera obedece a um comportamento sazonal verificando-se a maior incidência nos meses quentes e chuvosos. Porém, a seca de 1991-1992, na África Austral, trouxe graves consequiências. A perda da colheita agrícola, falta de água para o consumo humano e a ruptura das reservas alimentares, aumentou a vulnerabilidade da população já debilitada pela guerra e a crônica situação de emergência. Como conseqüência da seca, o número de pessoas em situação de emergência passou de 1.830 .000 , em 1991, para 3.150.000, em 1992. O abastecimento da água nas áreas afetadas era criticamente baixa. Por exemplo, o caudal do rio Pungue, na província de Sofala, desceu a quase $1 \%$, afetando seriamente a localidade de Dondo e a Cidade da Beira. $\mathrm{Na}$ zona rural da província de Sofala foi estimado que $75 \%$ das fontes superficiais e $25 \%$ das fontes profundas secaram $* * *$. O mesmo aconteceu na província de Maputo, com o rio Incomati, e na província de Gaza, com o rio Limpopo. Tanto nas zonas rurais como urbanas, a população optou pela procura de novas fontes de água. Começaram a aparecer novos poços em zonas de alta concentração de latrinas e sem nenhuma medida de proteção. Apesar de não ter sido possível realizar investigações epidemiológicas que ajudassem a identificar os fatores de risco na propagação da cólera devido a escassez de recursos, o inadequado abastecimento de água, em quantidade e qualidade, pode ter contribuído na propagação da cólera em Moçambique, fato também encontrado durante a epidemia no Peru, nos anos 1991 e 1992, a qual teve uma forte relação com a falta de tratamento de água canalizada e fontes de água contaminadas $7,9,10$.

$\mathrm{Na}$ realidade, a cólera está associada ao subdesenvolvimento. A maioria dos casos e óbitos reportados no mundo correspondem aos países do terceiro mundo; alguns casos foram notificados nos Estados Unidos, dos quais 17 tinham relação com a epidemia na América Latina; e 93 eram casos notificados como importados do Japão 8 . 
É indubitável que a rapidez do intercâmbio internacional tem favorecido a disseminação da doença no mundo, mas não se pode esquecer que $\circ \mathrm{V}$. cholerae EL TOR, com todas as suas características de endemicidade, tem encontrado nos países subdesenvolvidos as condições favoráveis para a sua propagação e permanência.

\section{Conclusões}

A cólera em Moçambique tem tomado características de endemicidade, com um marcado aumento do número de casos e uma rápida propagação em 1991 e 1992, como resultado de uma situação concreta. Isso, devido a um conjunto de fatores, tais como: crescimento populacional urbano descontrolado, provocado pela guerra com a consequiente piora das condições higiênico-sanitárias; comercialização de produtos alimentares sem o devido controle sanitário, e a seca. Esses fatores, acumulando-se e reproduzindo-se no tempo provocaram, ante a presença do $V$. cholerae EL TOR, uma disseminação incontrolável, afetando grande parte do território nacional. Mas que não se trata somente do produto da transmissão de um agente etiológico infectando os indivíduos. É também produto de uma grave situação de pobreza. De fato, esta realidade não surpreende. Depois de quase 5 séculos de influência ocidental, Moçambique ainda vive em condições similares às que vivia o mundo ocidental no período das grandes epidemias. Portanto, é desnecessário dizer que a solução desse problema não é de exclusiva responsabilidade do setor de saúde. As alternativas estão no desenvolvimento, responsibilidade essa dos governos e das políticas econômicas internacionais.

ARAGÓN, M. et al. [Cholera epidemiology in Mozambique: period 1973-1992]. Rev. Saúde Pública, 28: 332-36, 1994. The results of an epidemiological analysis of cholera in Mozambique from 1973 to 1992 are described. The project sought to assess the influence of socio-economic and ecological factors the spread of cholera in a country at war. Information about the incidence of cholera and the fatality rate were related to the rainfall and the annual average growth rate of the population in the main cities. Water supply, sanitation and food hygiene were also atudied. The high annual average growth rate of the population was found to have a direct linear correlation to the incidence of cholera. The drought of 1991-1992 also played an important role in the increased number of cases of the disease. Cholera has presented an endemic-epidemic pattern determined by: a) the uncontrolled growth of urban population, b) the deterioration of sanitation in urban centers, c) the unhygienic commercialization of food and d) the drought.

Keywords: Cholera, epidemiology. Socioeconomic factors.

\section{Referências Bibliográficas}

1. ARAUUJO, M. Distribuição geográfica da população e processo de urbanização. Maputo, Departamento de Geografia da Universidade Eduardo Mondlane, 1992.

2. BARTLETT, A. Cholera lessons. Lancet, 338:1216, 1991.

3. CLIFF, J. L. A hospital outbreak of cholera in Maputo, Mozambique. Trans. R. Trop. Med. Hyg., 80:473-6, 1986.

4. COLLINS, A. Environmental Influences on the distribution of incidence of cholera: a case study in Quelimane, Mozambique. London, Department of Geography - King's College, 1992.

5. FABRE-TESTE, B. et al. Etude comparative de deux épidémies de choléra dans province du Sofala (Mozambique), 19901991. Cah. Santé, 2:307-19, 1992.

6. MOREN, A. et al. Practical field epidemiology to investigate a cholera outbreak in a Mozambique refugee camp in Malawi, 1988. J. Trop. Med. Hgy., 94:1-7, 1991.

7. RIES, A. et al. Cholera in Piura, Peru: a modern urban epidemic. J. Infect. Dis., 166:1429-33, 1992.

8. SIMEANT, S. Choléra, 1991: viel ennemi, nouveau visage. World Health Stat. Q., 45:208-19, 1992.

9. SWERDLOW, D. et al. Waterborn transmision of epidemic cholera in Trujillo, Perú: lessons for a continent at risk. Lancet, 340:28-32, 1992.

10. TAMPLIN, M. et al. Environmental spread of vibrio cholerae in Peru. Lancet, 338:1216-7, 1991.

11. UNICEF. Situação mundial da infância: 1993, Brasília, 1993.

12. WORLD HEALTH ORGANIZATION. Cholera in África. Wkly Epidemiol. Rec., 66(42):305-11.

13. WORLD HEALTH ORGANIZATION. Guidelines for cholera control. Geneva, 1992 (WHO/CDD/SER/80.4, REV.4)

14. WORLD HEALTH ORGANIZATION. Principles and practice of cholera control. Geneva, 1970. (Public Health Paper, 40).

Recebido para publicação em 13.10.1993

Reapresentando em 11.7.1994

Aprovado para publicaçũo em 4. 8. 1994 